\title{
Occurrence and Risk Factors of Renal Artery Stenosis in Patients Undergoing Abdominal Computed Tomography Angiography, a One-Year Study in a Tertiary Hospital in Manila
}

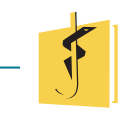

\section{Francis Angelo D. Basilio, MD}

\section{ABSTRACT}

Renal artery stenosis (RAS) is one of the most common primary diseases of the renal arteries. It is associated with hypertension as well as ischemic renal disease. Its concomitant presence constitutes a high cardiovascular risk, thus timely diagnosis is important. This study aims to determine the occurrence of RAS in patients undergoing abdominal CT angiography and determines other factors that predict the highest-risk subset who have significant renal artery narrowing. A retrospective review of records of 470 patients who underwent CT angiography of the whole abdomen was done. RAS occurs in about $9.57 \%$ of patients who had a CT scan of the whole abdomen. Older patients, patients with heart disease and patients with more atherosclerotic vessels in the abdomen increases the risk for significant RAS ( $p$ values of $0.005,0.008$ and $<0.001$, respectively). Diabetes, hypertension as well as other imaging findings such as the presence of aneurysm elsewhere seen in the abdominal scans and renal

Francis Angelo D. Basilio

fadbasilio.md@gmail.com

Department of Radiological Sciences University of Santo Tomas Hospital, Manila, Philippines artery duplication do not statistically correlate with the increased risk for RAS in this study.

Keywords: renal artery stenosis, CT angiography, atherosclerosis, fibromuscular dysplasia, hypertension

\section{INTRODUCTION}

Renal artery stenosis (RAS) is one of the most common primary diseases of the renal arteries, which is usually caused either by fibromuscular dysplasia or atherosclerosis. $[5,11]$ It is associated with hypertension as well as ischemic renal disease.[8]

A large majority of studies performed in the prevalence of RAS are in patients with high-risk factors such as hypertension, peripheral vascular disease or renal insufficiency. No studies have been made at the population level which would demand a simple and reliable screening test. This problem is relevant because hemodynamically significant RAS may also be seen in patients with normal blood pressure, normal renal function and may occur at an early age.[6] The prevalence of RAS also depends on several factors which include the degree of investigation. This is likely to increase with the widespread use of non-invasive tests.[7] 
Its concomitant presence constitutes a high cardiovascular risk, thus timely diagnosis is important. [9] This study aims to determine the occurrence of RAS in patients undergoing abdominal CT angiography and determine other factors that predict the highest-risk subset who have significant renal artery narrowing.

\section{METHODOLOGY}

A retrospective review of records and CT scan images of all patients above 18 years old who underwent a CT scan of the whole abdomen was done in a 1-year period (April 2016 to April 2017). All studies were performed in an angiographic protocol obtained at peak enhancement from the celiac axis during a single breath-hold with $120 \mathrm{kVp}$ and 260-280 mAs, given $100 \mathrm{~mL}$ of contrast material infused at $4-5 \mathrm{~mL} / \mathrm{sec}$.[10]

The exclusion criteria includes patients with technically inadequate images because of either poor opacification of the renal vessels, patients with surgical procedures related to the kidney and its vasculature and patients with renal/perirenal lesions affecting its vasculature.

The images were interpreted by two independent radiologists who are certified fellow of the Philippine College of Radiology and CT-MRI Society of the Philippines as well as an active member of the UST Hospital Department of Radiological Sciences. The radiologists were blinded by the official result.

The studies were evaluated for the presence of stenosis and its degree, which will be given a five-point ordinal scale: 0 for no stenosis, 1 for less than $50 \%$ stenosis, 2 for $50 \%-75 \%$ stenosis, 3 for greater than $75 \%$ stenosis and 4 for total occlusion (Figure 1-3). The associated clinical data and significant imaging findings were also tabulated.

\section{Statistical Analysis}

Mean, range and standard deviation summarized the data in quantitative form, such as age, eGFR and number of atherosclerotic vessels. Counts and percentages summarized the data in a categorical form such as gender, clinical characteristics (ie, number of patients with allergy, asthma, DM, heart disease, hypertension, stage 1 to 5 of CKD), and the imaging findings.

Univariate and multivariate logistic regression with stepwise variable elimination procedure determined the factors that lead to RAS.

Lastly, the intraclass coefficient (ICC) was computed for the inter-rater reliability of the two interpreters involved in the study.

All the statistical tests were performed using SPSS ver 20.0 , with a $5 \%$ level of significance.

\section{Ethical Considerations}

The approval to perform the study was obtained from the University of Santo Tomas, Institutional Review Board. Access to the records available in the department was approved by the Chief of Section of the CT-MRI unit, Chairman of the Department of Radiological Sciences and the Medical Director of the University of Santo Tomas Hospital. No informed consent was obtained from each subject as this is only a retrospective study.

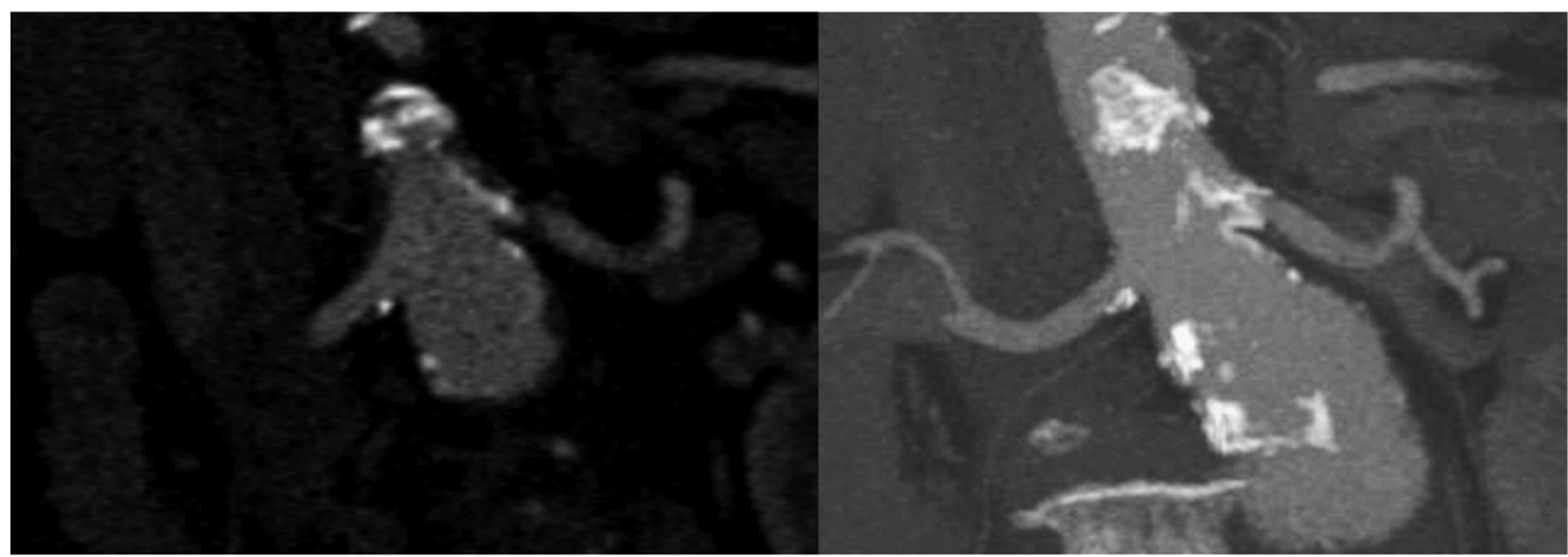

Figure 1: Renal artery stenosis grade 1. Thin slice and maximum intensity projection (MIP) images. 


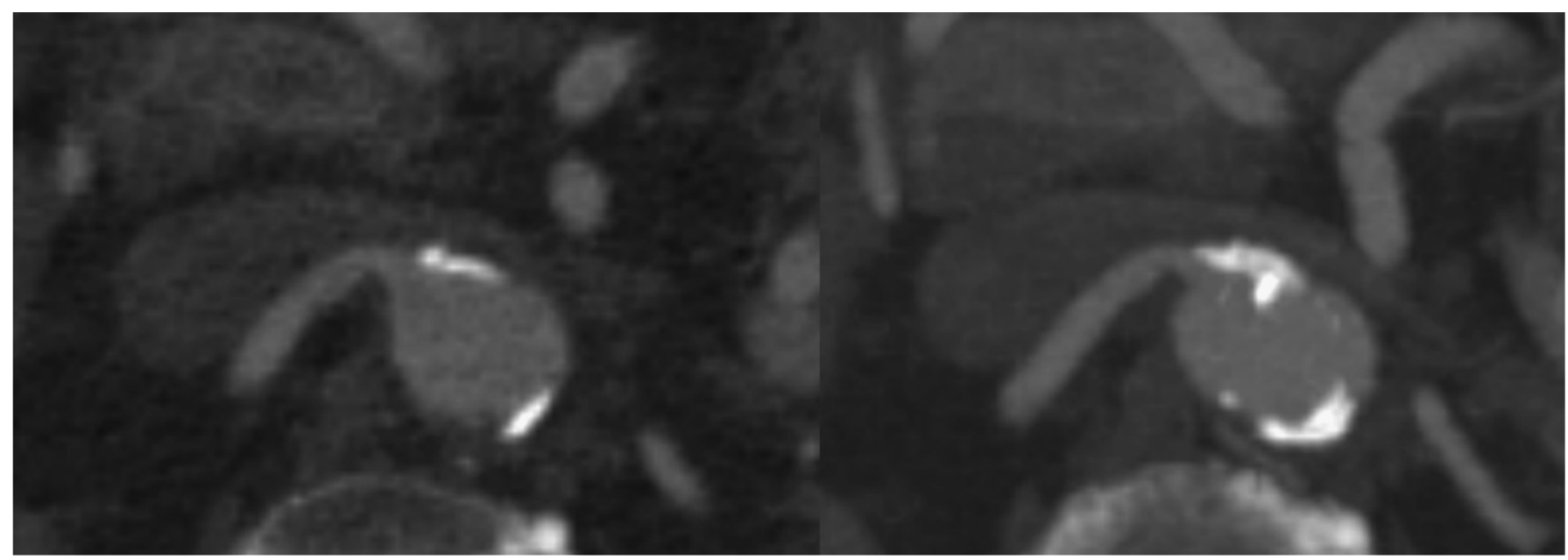

Figure 2a: Renal artery stenosis grade 2. Thin slice and maximum intensity projection (MIP) images.

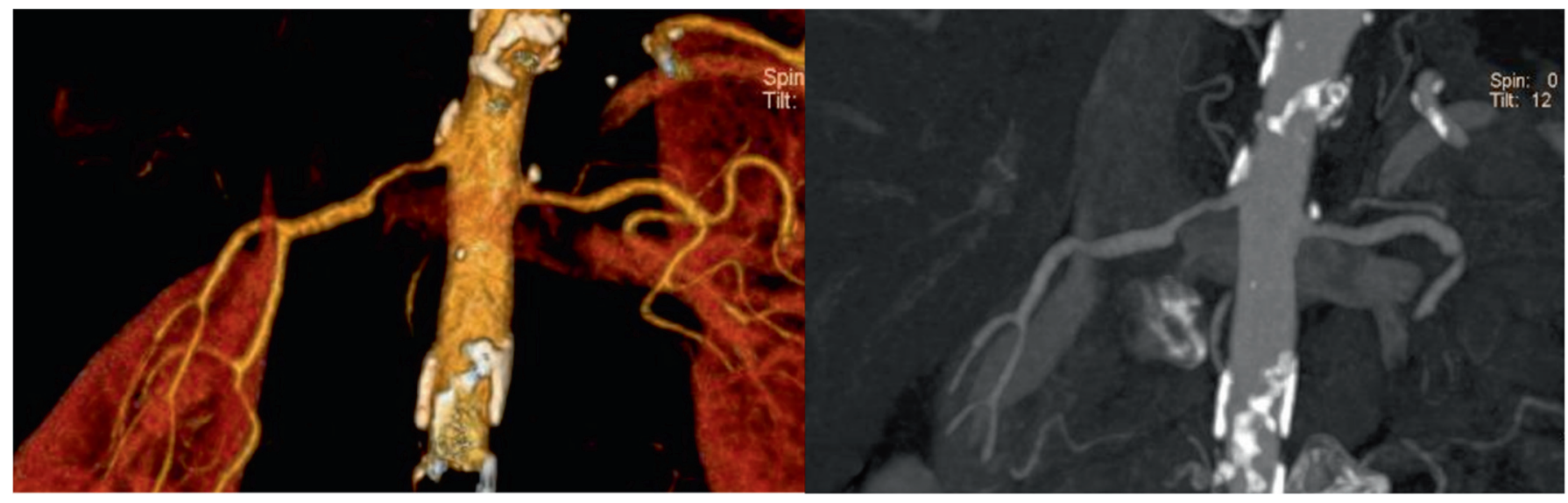

Figure 2b: Renal artery stenosis grade 2. maximum intensity projection (MIP) and volume-rendered images.
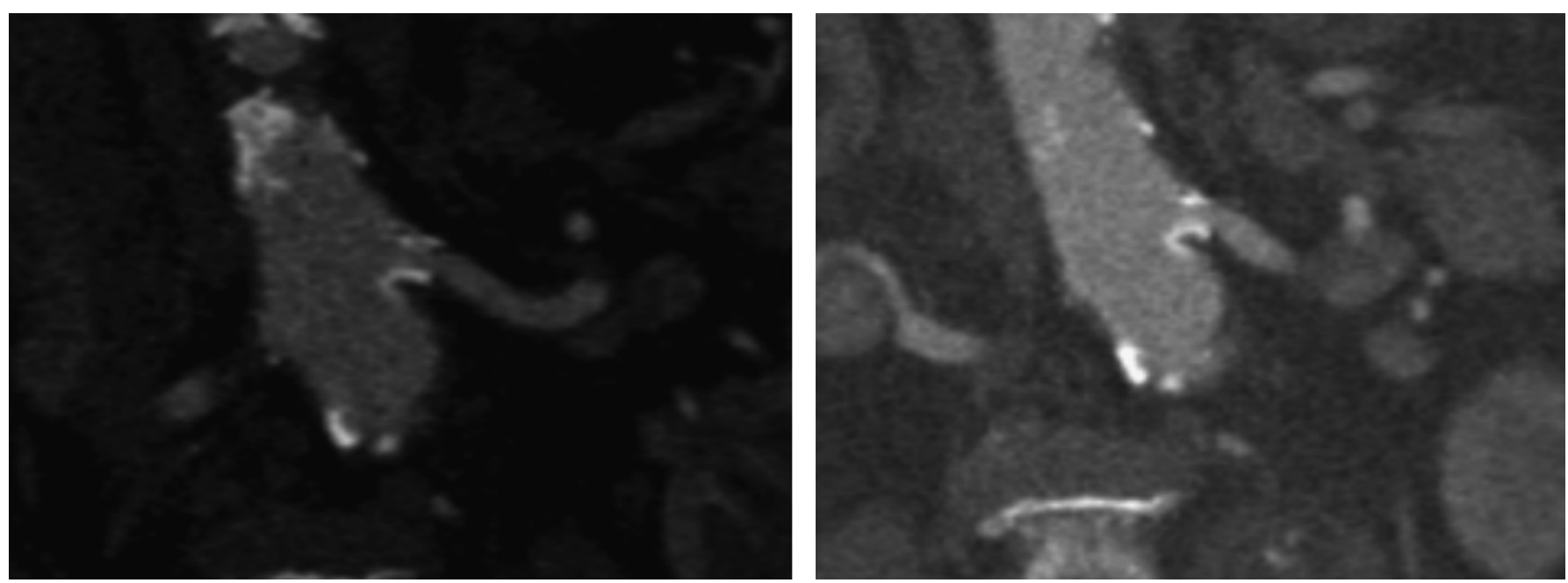

Figure 3: Renal artery stenosis grade 3. Thin slice and maximum intensity projection (MIP) images. 


\section{RESULTS}

There were 627 patients who underwent a CT scan of the whole abdomen during the study time period. Of these, 157 patients were excluded based on the exclusion criteria.

A total of 470 patients were included in the study with the mean age of 57.5 (range, 18 to 95). More than half $(n=238,50.6 \%)$ are female patients. The most common clinical findings are hypertension $(42.3 \%)$, diabetes mellitus $(25.1 \%)$ and allergy
(21.5\%). The comparison of patients with significant RAS (grade 2-3) and without RAS are presented in Table 1.

\section{Factors That Lead to RAS}

Results show that age $(p=0.004)$, heart disease $(p=0.008)$ and a number of atherosclerotic vessels $(p<0.001)$ are the only factors that predict the RAS. Multivariate logistic regression shows that age, heart disease and atherosclerotic vessels have an odds

Table 1. Demographics, clinical and imaging findings of patients with renal artery stenosis.

\begin{tabular}{|c|c|c|c|}
\hline & ALL & With RAS & Without RAS \\
\hline Number of Patients & 470 & 45 & 425 \\
\hline \multicolumn{4}{|l|}{ Demographics } \\
\hline Age (years) & $57.5(18-95)$ & $72.7 \pm 10.6$ & $55.9 \pm 16.4$ \\
\hline Gender: Male & $232(49.4 \%)$ & $24(53.3 \%)$ & $108(25.4 \%)$ \\
\hline \multicolumn{4}{|l|}{ Clinical Characteristics } \\
\hline Allergy & $101(21.5 \%)$ & $5(11.1 \%)$ & $96(22.6 \%)$ \\
\hline Asthma & $55(11.7 \%)$ & $4(8.9 \%)$ & $51(12 \%)$ \\
\hline Diabetes Mellitus & $118(25.1 \%)$ & $18(40 \%)$ & $100(23.5 \%)$ \\
\hline Heart Disease & $43(9.1 \%)$ & $13(28.9 \%)$ & $30(7.1 \%)$ \\
\hline Hypertension & $199(42.3 \%)$ & $29(64.4 \%)$ & $170(40 \%)$ \\
\hline eGFR (in $\mathrm{mL} / \mathrm{min} / 1.73 \mathrm{~m}^{2}$ ) & $88.8(6-1117)$ & $70.2 \pm 22.9$ & $90.7 \pm 56.2$ \\
\hline \multicolumn{4}{|l|}{ Chronic Kidney Disease stage } \\
\hline 5 & $12(2.6 \%)$ & $3(6.7 \%)$ & $9(2.1 \%)$ \\
\hline 4 & $55(11.7 \%)$ & $8(17.8 \%)$ & $47(11.1 \%)$ \\
\hline 3 & $101(21.5 \%)$ & $15(33.3 \%)$ & $86(20.2 \%)$ \\
\hline 2 & $162(34.5 \%)$ & $17(37.8 \%)$ & $145(34.1 \%)$ \\
\hline 1 & $140(29.8 \%)$ & $2(4.4 \%)$ & $138(32.5 \%)$ \\
\hline \multicolumn{4}{|l|}{ Imaging Findings } \\
\hline Aorta & $321(68.3 \%)$ & $44(97.8 \%)$ & $277(65.2 \%)$ \\
\hline Iliac & $267(56.8 \%)$ & $43(95.6 \%)$ & $224(52.7 \%)$ \\
\hline Splenic & $35(7.4 \%)$ & $15(33.3 \%)$ & $20(4.7 \%)$ \\
\hline Celiac & $10(2.1 \%)$ & $7(15.6 \%)$ & $3(0.7 \%)$ \\
\hline Superior mesenteric artery(SMA) & $35(7.4 \%)$ & $17(37.8 \%)$ & $18(4.2 \%)$ \\
\hline Number of Atherosclerotic Vessels & $1.4(0-5)$ & $2.8 \pm 1.1$ & $1.3 \pm 1.1$ \\
\hline Aneurysm & $8(1.7 \%)$ & $2(4.4 \%)$ & $6(1.4 \%)$ \\
\hline Duplication: Left & $51(10.9 \%)$ & $6(13.3 \%)$ & $45(10.6 \%)$ \\
\hline Right & $36(7.7 \%)$ & $3(6.7 \%)$ & $33(7.8 \%)$ \\
\hline
\end{tabular}

Values are expressed as mean (range), mean $\pm \mathrm{SD}$, or counts $(\%)$. 
Table 2. Logistic regression results of patients with renal artery stenosis

\begin{tabular}{lcc}
\hline & Univariate & Multivariate \\
\hline Demographics & $1.09(1.06-1.12)$ & $1.05(1.02-1.09)$ \\
Age (years) & $1.19(0.64-2.21)$ & \\
Gender: Male & $0.43(0.17-1.12)$ & \\
Clinical Characteristics & $0.72(0.25-2.08)$ & \\
$\quad$ Allergy & $2.17(1.15-4.10)$ & $3.10(1.34-7.18)$ \\
Asthma & $5.35(2.54-11.25)$ & \\
Diabetes Mellitus & $2.72(1.43-5.16)$ & \\
Heart Disease & $0.97(0.96-0.99)$ & \\
Hypertension & & \\
eGFR (in mL/min/1.73m²) & $23.51(3.21-172.35)$ & \\
Imaging Findings & $19.29(4.62-80.66)$ & \\
Aorta & $10.13(4.71-21.77)$ & \\
Iliac & $25.91(6.44-104.31)$ & \\
Splenic & $13.73(6.39-29.52)$ & \\
Celiac & $3.36(2.40-4.71)$ & \\
SMA & $3.25(0.64-16.59)$ & \\
Number of Atherosclerotic Vessels & $9.64(0.59-156.75)$ & \\
Aneurysm & Small Bilateral &
\end{tabular}

Values displayed are the odds ratio $(95 \% \mathrm{Cl})$. Variables in the multivariate logistic regression without odds ratio displayed indicate an eliminated variable.

ratio of $1.05(95 \% \mathrm{Cl}: 1.02-1.09), 3.10(95 \% \mathrm{Cl}$ : $1.34-7.18)$ and $2.55(95 \% \mathrm{Cl}: 1.75-3.73)$, respectively.

\section{Inter-Rater Reliability}

The two interpreters had weighted Kappa $=0.62$ $(p<0.001)$ in giving scores to the patient's left and weighted Kappa $=0.66(p<0.001)$ in giving scores to the patient's right kidney. This indicates that the two interpreters moderately agree in giving scores to patients.

\section{Characteristics of Patients With RAS}

There are five patients with bilateral RAS and 40 patients with unilateral RAS. Among the five patients with bilateral RAS, two had both scores of 3 in both kidneys, while two had scores of 2 in both kidneys. One patient had a score of 2 on the left and 3 on the right kidney. Meanwhile, 20 patients had RAS on the left side, with 6 of them of grade 3 while 14 patients had a grade of 2 . Another 20 patients had
RAS on the right side, with 6 of them of grade 3 and 14 of them with a grade of 2 .

Regarding the location, $44(88 \%)$ of RAS were found at the ostium. Other locations (12\%) include the main artery and segmental branches.

\section{DISCUSSION}

Based on the data gathered, this implies that older patients, patients with heart disease and patients with more atherosclerotic vessels in the abdomen increases the risk for significant RAS ( $p$ values of $0.005,0.008$ and $<0.001$, respectively).

Multivariate logistic regression shows that one year increase in age increases the risk of RAS by five percent $(O R=1.05 ; 95 \% \mathrm{Cl}: 1.02-1.09)$. Other studies also noted an increasing incidence of older than 50 years. [2]

For every one vessel (among the abdominal aorta, celiac, splenic, SMA and iliac arteries) with atherosclerotic changes, the odds of having RAS increases by a factor of $2.55(O R=2.55$; $95 \% \mathrm{Cl}: 1.75-3.73)$. This also corresponds 
with studies correlating peripheral artery disease $[1,3,6,13]$ and coronary artery disease (CAD) [12] with RAS.

Patients with heart disease are 3.10 times $(O R=$ $3.10 ; 95 \% \mathrm{Cl}: 1.34-7.18)$ more likely to have RAS compared to patients without heart disease. A study by Yamashita, et al. also found RAS in non-CAD patients, such as patients with valvular heart disease $(12 \%)$ and cardiomyopathy $(7 \%)$.

Eighteen patients among 118 patients with diabetes and 29 patients among 200 patients with hypertension had RAS. However, diabetes and hypertension did not statistically correlate with increased risk for RAS in this study. Also, renal function as reflected by eGFR and CKD stage did not statistically correlate with the presence of RAS. The population in this study is not those of the high-risk population such as in patients undergoing coronary angiography, hypertensive and CKD patients, which might probably affect the results of the study. Hence, this might probably explain the data discrepancy in other studies.

Other imaging findings such as the presence of aneurysm elsewhere seen in the abdominal scans and renal artery duplication show no correlation with RAS.

Most of the stenosis was found near the ostium of the renal arteries (88\%). Yoon, et al. also showed that RAS is typically seen at the origin or within the proximal $2 \mathrm{~cm}$ of the renal artery. [4] Bilateral lesions were only seen in $10 \%$ of patients in this study.

\section{CONCLUSION}

The data derived from this single-center tertiary hospital study indicated that RAS occurs in about $9.57 \%$ of patients with a CT scan of the whole abdomen. Older patients, patients with heart disease and patients with more atherosclerotic vessels in the abdomen increases the risk for significant RAS ( $p$ values of $0.005,0.008$ and $<0.001$, respectively). Diabetes, hypertension as well as other imaging findings such as the presence of aneurysm elsewhere seen in the abdominal scans and renal artery duplication do not statistically correlate with increased risk for RAS in this study.

\section{RECOMMENDATION}

The study was retrospectively done with limited clinical data gathered during the time of examination. Other risk factors such as body weight, smoking history and other atherosclerotic diseases such as in the central nervous system and peripheral blood vessels were not available and hence were not sought in this study. No data regarding other details on the history of hypertension were available including the length, control and stage which may be valuable to the analysis. Further, no details regarding what heart disease were indicated in the data. The researchers recommend doing a prospective study that will be able to gather more clinical findings of the patients.

The number of atherosclerotic vessels among the major branches of the aorta and most common arteries to show atherosclerotic changes is not a standardized method to measure the degree of atherosclerosis. However, there were no methods known to the researchers to do this, such as those in the coronary arteries (calcium scoring). The study somehow reflects the degree of atherosclerosis as it is correlated with the presence of RAS. A further study may be done to evaluate this measure.

A high-risk population study using age, heart disease and the number of atherosclerotic vessels may also be done to further evaluate this patient population. 


\section{REFERENCES}

1. Granata A, Fiorini F, Andrulli S, Logias F, Gallieni M, Romano $G$, et al. Doppler ultrasound and renal artery stenosis: An overview. Journal of Ultrasound. 2009; 12(4):133-43.

2. Yamashita $T$, Ito F, Iwakiri N, Mitsuyama H, Fujii S, Kitabatake A. Prevalence and predictors of renal artery stenosis in patients undergoing cardiac catheterization. Hypertension Research. 2002;25(4):553-7.

3. Aboyans V, Desormais I, Magne J, Morange G, Mohty D, Lacroix P. Renal artery stenosis in patients with peripheral artery disease: prevalence, risk factors and long-term prognosis. European Journal of Vascular and Endovascular Surgery. 2017;53(3):380-5.

4. Harding MB, Smith LR, Himmelstein SI, Harrison K, Phillips $H R$, Schwab SJ, et al. Renal artery stenosis: prevalence and associated risk factors in patients undergoing routine cardiac catheterization. Journal of the American Society of Nephrology. 1992;2(11):1608-16.

5. Al-Katib S, Shetty M, Jafri SM, Jafri SZ. Radiologic assessment of native renal vasculature: a multimodality review. RadioGraphics. 2017;37(1):136-56.

6. Zoccali C. Atherosclerotic renal artery stenosis: epidemiology, cardiovascular outcomes, and clinical prediction rules. Journal of the American Society of Nephrology. 2002;13 Suppl 3:S179-83.

7. Claudon M, Plouin PF, Baxter GM, Rohban T, Devos DM. Renal arteries in patients at risk of renal arterial stenosis: multicenter evaluation of the echo-enhancer $\mathrm{SH}$ U 508A at color and spectral Doppler US. Radiology. 2000;214(3):739-46.

8. Gilfeather M, Yoon H, Siegelman ES, Axel L, Stolpen AH, Shlansky-Goldberg RD, et al. Renal artery stenosis: evaluation with conventional angiography versus gadolinium-enhanced MR angiography. Radiology. 1999;210(2):367-72.

9. Ota H, Takase K, Rikimaru H, Tsuboi M, Yamada T, Sato A, et al. Quantitative vascular measurements in arterial occlusive disease. RadioGraphics. 2005;25(5):1141-58.

10. Johnson PT, Halpern EJ, Kuszyk BS, Heath DG, Wechsler RJ, Nazarian LN, et al. Renal artery stenosis: CT angiographycomparison of real-time volume-rendering and maximum intensity projection algorithms. Radiology. 1999;21 1 (2):337-43.

11. Olin JW. Renal artery disease: diagnosis and management. Mt Sinai J Med. 2004;71(2):73-85.

12. Tafur JD, White CJ. Renal artery stenosis: when to revascularize in 2017. Current Problems in Cardiology. 2017;42(4), 110-35.

13. Wachtell K1, Ibsen $H$, Olsen MH, Laybourn C, Christoffersen JK, Nørgaard $\mathrm{H}$, et al. Prevalence of renal artery stenosis in patients with peripheral vascular disease and hypertension. J Hum Hypertens. 1996; 10(2):83-5.

cc (i) Open Access This article is licensed under a Creative Commons Attribution 4.0 International License, which permits use, sharing, adaptation, distribution and reproduction in any medium or format, as long as you give appropriate credit to the original author(s) and the source, provide a link to the Creative Commons license, and indicate if changes were made. The images or other third party material in this article are included in the article's Creative Commons license, unless indicated otherwise in a credit line to the material. If material is not included in the article's Creative Commons license and your intended use is not permitted by statutory regulation or exceeds the permitted use, you will need to obtain permission directly from the copyright holder. To view a copy of this license, visit http://creativecommons.org/licenses/by/4.0/. 